\title{
Dynamic study of milling low depth channels
}

\author{
Dorin Mircea Rosca $^{1}$, Mircea Anton Vasiloni, and Milena Folea ${ }^{1, *}$ \\ ${ }^{1}$ Transilvania University of Brasov, Department of Manufacturing Engineering, Mihai Viteazu No.5, \\ Braşov, Romania
}

\begin{abstract}
This paper presents a study of dynamic aspects of the milling cutters used in particular case of low depth channels. A new calculation method was developed, taking into account the high variations of cutting forces during milling small depth channels with peripheral cutting tools. A new formula was established for the minimal value of channel depth that allows cutting process to be performed in conditions of dynamic stability.
\end{abstract}

\section{Introduction}

It is known that the mechanical and thermal stresses of a technological system for cutting processes are influenced by many factors. Thus, in case of milling a very important factor is the way chips are removed: peripheral milling or face milling.

Disk-cutters studied in this paper being provided with a single row of cutting edges on the cylindrical surface will fit in the first category. Chips detached through peripheral milling have variable thickness and their cross sections are defined by two cycloid curves described by points in the edge of the cutter. Evidently, the variable thickness of the chip causes the variation in time of components of total cutting force and milling torque [1]. Because from a practical point of view the most eloquent dynamic indicator in milling is torque, $M_{t}$, this variable will be studied through this paper.
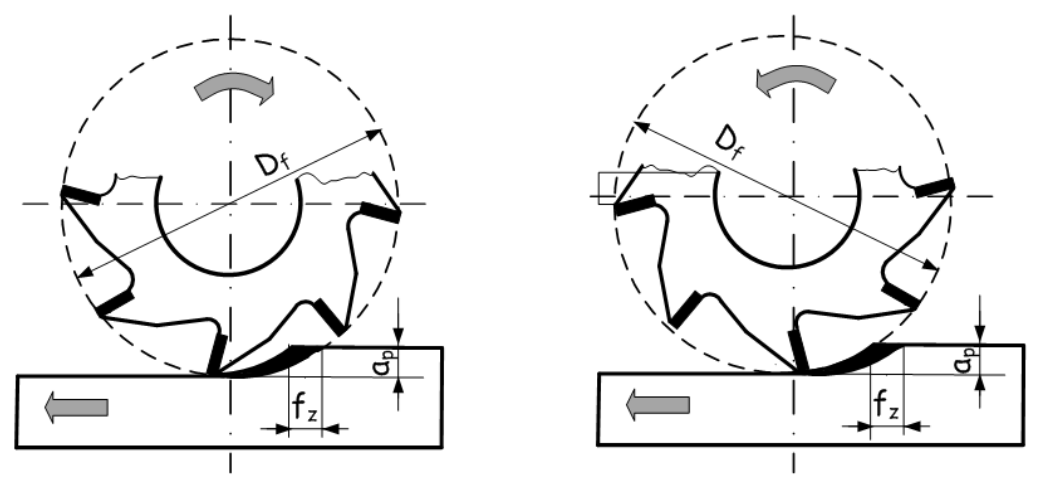

Fig. 1. Down milling (left) and up milling (right).

\footnotetext{
*Corresponding author: m.folea@unitbv.ro
} 
This study will also focus on small width disk-type milling cutters known as slitting cutters. If this type of tool is used for the execution channels/grooves, milling method recommended in the literature [1-3] it is "down milling" and if the cutter is designed for parting operation (slitting), the optimum method is "up milling" (Fig. 1).

Whatever the method of milling, more teeth of the cutter are simultaneously in contact with the workpiece, their number, $z_{0}$, depending on the depth channel milling, on tool diameter $\left(D_{f}\right)$ and the total number of teeth $(z)$. By periodically entering and leaving the material by cutting edges results an oscillatory behaviour for cutting force and milling torque.

Since in cutting tools catalogues [1] are only indicated maximal depths of cut for slitting and considering that in case of peripheral milling narrow and small depth channels it would be appropriate to indicate also the minimal depth of cut in order to improve dynamic conditions, the aim of this paper is to determine those minimal values that avoid shock of milling cutter teeth when entering in workpiece material.

\section{Calculation and analysis of milling torque}

Considering one moment in time of milling process with a slitting cutter with straight teeth $\left(\omega=0^{\circ}\right)$, axial cross sections (0-1, 0-2 etc.) of the chips removed by the three teeth (Fig. 2$)$ have rectangular shapes, their thickness being calculated as functions of feed per tooth $\left(f_{z}\right)$ and contact angle $(\varphi)$ by the following relations:

$$
\begin{array}{r}
\quad a_{1}=f_{z} \cdot \sin \varphi \\
a_{2}=f_{z} \cdot \sin (\varphi-\delta) \\
a_{3}=f_{z} \cdot \sin (\varphi-2 \delta)
\end{array}
$$

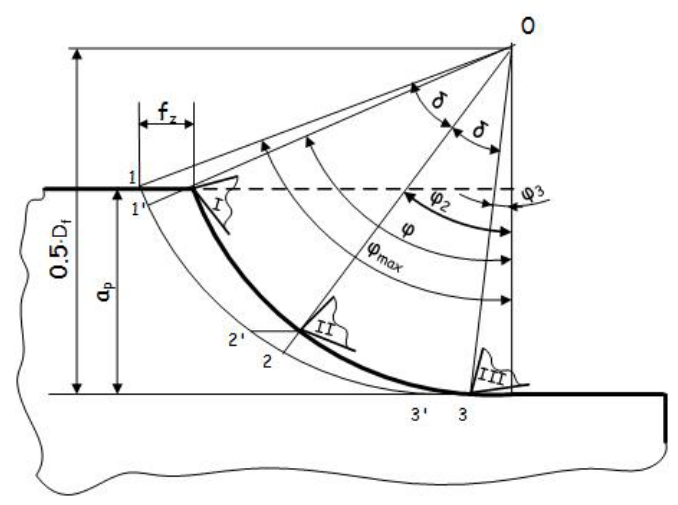

Fig. 2. Up milling with three teeth engaged in cut.

Milling process being type "up milling", the maximum value for milling torque is recorded shortly before the exit from cutting of tooth number 1and can be determined as follows:

$$
M_{t \max }=\frac{D_{f}}{2}\left(B \cdot a_{1} \cdot k_{s_{1}}+B \cdot a_{2} \cdot k_{s_{2}}+B \cdot a_{3} \cdot k_{s_{3}}\right)
$$

where

$\mathrm{B}$ is processed width (channel width);

$k_{s_{1}}, k_{s_{2}}, k_{s_{3}}$ specific force corresponding to chip thickness $a_{1}, a_{2}$ and $a_{3}$. 
If $k_{s_{1}}, k_{s_{2}}$ and $k_{s_{3}}$ are replaced in equation (4), defining them relative to specific force per unit $k_{s_{1,1}}$ is obtained:

$$
M_{t \max }=\frac{B \cdot D_{f} \cdot k_{s_{1.1}}}{2}\left(a_{1} \cdot a_{1}^{-z} \cdot k_{s_{1.1}}+a_{2} \cdot a_{2}^{-z} \cdot k_{s_{1.1}}+a_{2} \cdot a_{2}^{-z} \cdot k_{s_{1.1}}\right)
$$

respectively,

$$
M_{t \max }=\frac{B \cdot D_{f} \cdot k_{s_{1.1}}}{2}\left(a_{1}^{(1-z)}+a_{2}^{(1-z)}+a_{3}^{(1-z)}\right)
$$

After in equation (6) are introduced relations (1), (2) and (3) final mathematical form of the torque results as:

$$
M_{t \max }=\frac{B \cdot D_{f} \cdot k_{s_{1,1}} \cdot f_{z}^{(1-z)}}{2}\left[\sin ^{(1-z)} \varphi+\sin ^{(1-z)}(\varphi-\delta)+\sin ^{(1-z)}(\varphi-2 \delta)\right]
$$

for the particular case when the maximum number of teeth of a disk-type milling cutter with $\omega=0^{\circ}$ simultaneously engaged in cutting is $\mathrm{z}_{0}=3$.

Generalizing the equation (7) for a number "i" of teeth simultaneously engaged in cutting is obtained:

$$
M_{t \max }=\frac{B \cdot D_{f} \cdot k_{s_{1,1}} \cdot f_{z}^{(1-z)}}{2}\left\{\sin ^{(1-z)} \varphi+\sin ^{(1-z)}(\varphi-\delta)+\ldots+\sin ^{(1-z)}\left[\varphi-\left(z_{i}-1\right) \delta\right]\right\}
$$

According to equation (8), the maximum torque is obtained by adding "i" sinusoidal functions at power $(1-z)$. In table 1 are indicated approximate values for the exponent $(1-z)$ for various materials processed by milling [4]:

Table 1.Coefficient $z$ for various materials

\begin{tabular}{|c|c|c|c|c|c|c|c|c|}
\hline $\begin{array}{c}\text { Workpiece } \\
\text { material }\end{array}$ & $\mathbf{C 4 5}$ & $\mathbf{C 7 0}$ & $\mathbf{1 5 C N 1 5}$ & $\mathbf{3 3 M o C 1 1}$ & $\mathbf{5 0 V C 1 1}$ & $\begin{array}{c}\text { Cast } \\
\text { iron }\end{array}$ & $\begin{array}{c}\text { Brass with } \\
\mathbf{\sigma}_{\mathbf{r}}=\mathbf{5 0 0} \mathbf{M P a}\end{array}$ & $\begin{array}{c}\text { Aluminium } \\
\text { alloys }\end{array}$ \\
\hline$(1-\mathrm{z})$ & 0.88 & 0.79 & 0.74 & 0.84 & 0.80 & 0.81 & 0.66 & 0.66 \\
\hline
\end{tabular}

Cutting tool suppliers present in their catalogues various disk-type milling cutters with or without inserts that are used for slitting or peripheral slotting. Present paper refers only to disk-cutters with maximum width of $5 \mathrm{~mm}$ and with maximum length of tooth cutting edge also of $5 \mathrm{~mm}$.

In order to obtain a more uniform load during processing with disk-type milling cutters with straight teeth, a minimal condition must be satisfied $[4,5]$ : on the contact arc " $\varphi$ " there must be at least two teeth. In the case of small depth channels there may be just one tooth engaged in cutting at a time. In this case the torque will have a pulsating and cyclic variation as in Fig. 3 for down milling or as in Fig. 4 for up milling. 


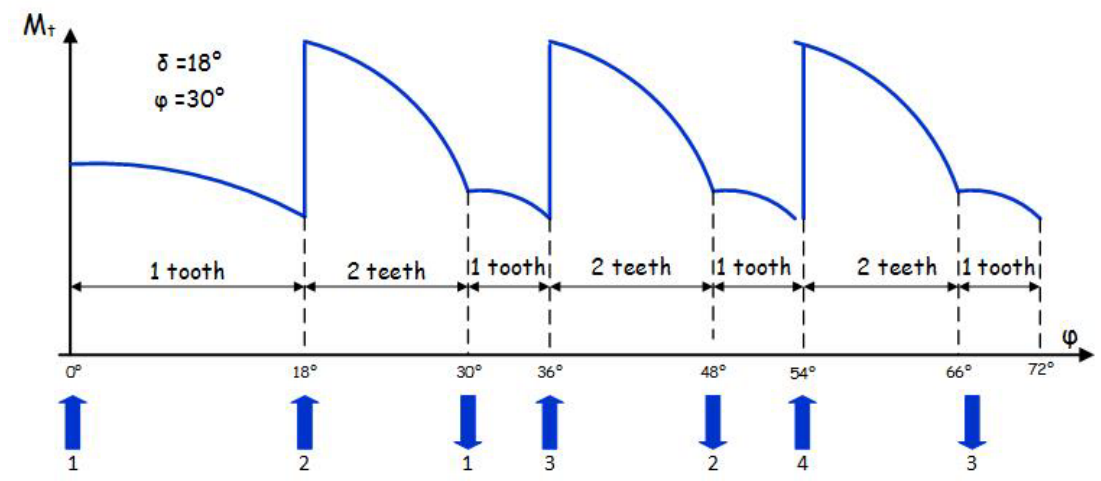

Fig. 3.Torque variation during down milling with one tooth and two teeth engaged in cutting.

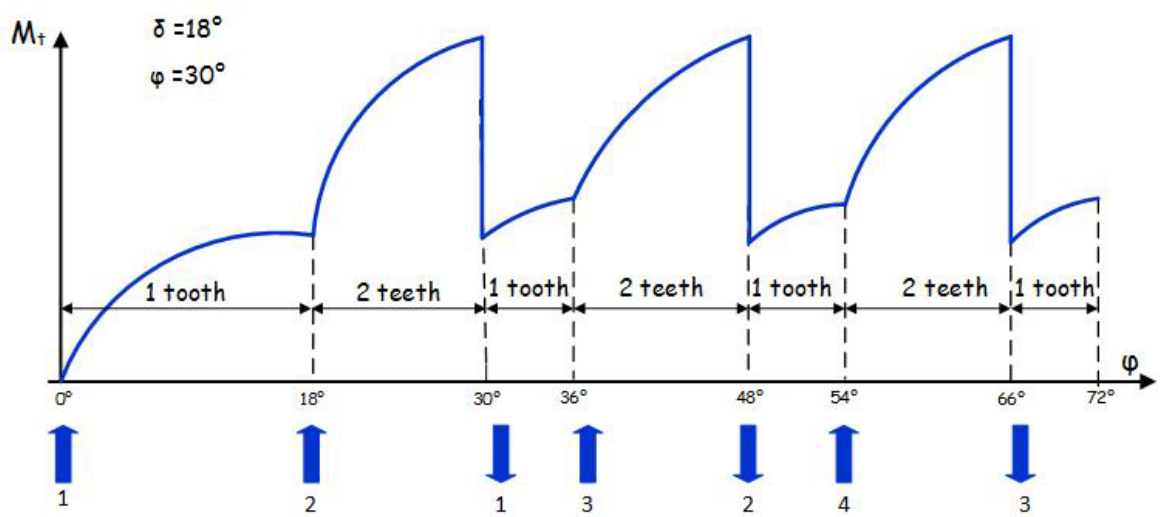

Fig. 4.Torque variation during up milling with one tooth and two teeth engaged in cutting.

It is important to reveal that by indicating in tool catalogues only the maximum depth of channel/groove processed with a slitting tool, stability issues are neglected in case of small depth channels. Until now, there is only mentioned the maximum depth of the cut [69].Therefore, some representative types of narrow disk-type milling cutters were selected and minimal values for the depth of the channel $h_{\min }$ were calculated for situations when at least one tooth of the milling cutter is permanently in contact with the workpiece. As can be observed in Table $2, h_{\min }$ depends both on outer diameter $D_{f}$ and on the number teeth $z$ of the tool.

Table 2.Calculated values of $h_{\min }$

\begin{tabular}{|c|c|c|c||c|c|c|c|}
\hline $\begin{array}{c}\mathbf{N r} \\
\mathbf{c r t .}\end{array}$ & $\begin{array}{c}\mathbf{D}_{\mathbf{f}} \\
{[\mathbf{m m}]}\end{array}$ & $\mathbf{z}$ & $\begin{array}{c}\mathbf{h}_{\mathbf{m i n}} \\
{[\mathbf{m m}]}\end{array}$ & $\begin{array}{c}\mathbf{N r} \\
\mathbf{c r t .}\end{array}$ & $\begin{array}{c}\mathbf{D}_{\mathbf{f}} \\
{[\mathbf{m m}]}\end{array}$ & $\mathbf{z}$ & $\begin{array}{c}\mathbf{h}_{\mathbf{m i n}} \\
{[\mathbf{m m}]}\end{array}$ \\
\hline 1 & 80 & 7 & 15.06 & 6 & 125 & 11 & 9.922 \\
\hline 2 & 80 & 8 & 11.715 & 7 & 160 & 13 & 9.163 \\
\hline 3 & 100 & 9 & 11.618 & 8 & 160 & 14 & 7.922 \\
\hline 4 & 100 & 10 & 9.549 & 9 & 200 & 17 & 6.753 \\
\hline 5 & 125 & 10 & 11.936 & 10 & 200 & 18 & 6.030 \\
\hline
\end{tabular}




\section{Conclusions}

The present study was justified by the fact that disk-type milling cutters of small width, with carbide inserts mechanically fixed, are provided with a number of teeth much lower than those made of high speed steel for a given outer diameter of the tool and stability problems might occur at low depth of processed channels/grooves.

In order to avoid shock over load of technological system during milling, an important measure to be taken is to diminish the variation of the cutting force and torque. In this respect, this paper provides for the specialists a method for calculating the maximum torque when milling using disc-type cutters. According to the new calculation formula, the maximum value of milling torque is obtained by summarizing a series of sinusoidal functions, one for the torque of each tooth engaged in cutting.

For a better protection from dynamic shocks of the technological equipment during milling narrow and small depth channels, it is strongly recommended to be indicated in the documentation of cutting tools suppliers, the minimum cutting depth which ensures at least one tooth permanently in contact with the workpiece.

\section{References}

1. L. Sauer, C. Ionescu, Cutting tools for milling [Scule pentru frezare] (Ed. Tehnica, Bucuresti, 1977)

2. S. Batt, Ein Beitrag zur Entwicklung von Fräswerkzeugen mit verbesserten dynamischen Schnitteigenschaften/ Universität Magdeburg, Dissertation Thesis, (2006)

3. N.B. Lupulescu, G. Oancea, A. Nedelcu, Computer aided design of cutting tools for metal milling [Proiectarea informatizata a sculelor pentru frezarea metalelor] (Ed. Lux Libris, Brasov, 2007)

4. D.M. Rosca, New Built-in-Conceptual aspects Regarding Cutting Tools Used in the Internal Surfaces Processing, AJME, 4(3), 53 (2006)

5. S. Enache, V. Belousov, Cutting tools designing [Proiectarea sculelor aschietoare] Ed. Didactica si pedagogica, Bucuresti, (1983)

6. ***PATENTSCHRIFT: ROTIERENDES Fräswerkzeug/ DE 10124234 B4, 2007

7. $* * *$ Cutting tools from Sandvick Coromant- Main catalogue (2012)

8. ***ISCAR tools e-catalogue (2016), accessed: May 2016, available at: http://www.iscar.com/eCatalog/Products.aspx?mapp=ML\&app=57

9. ***Walter General Catalogue (2012) 